\title{
Semiótica, música e organização do conhecimento: contribuindo para o debate
}

\author{
Semiotics, music and knowledge organization: contributions for the debate
}

\author{
Jozuel Vitorino de Moura \\ Doutorando em Ciência da Informação \\ Universidade Estadual Paulista \\ jozuelmoura@gmail.com \\ Carlos Cândido de Almeida \\ Doutor em Ciência da Informação \\ Universidade Estadual Paulista \\ carlos.c.almeida@unesp.br
}

\begin{abstract}
Resumo
Este estudo objetivou analisar o potencial informativo do campo da música sob a perspectiva da semiótica de Charles Sanders Peirce. A música se apresenta como um campo de diversas possibilidades informativas, compreendendo além de documentos e seus dados, o fenômeno observado por meio da experiência e do processo cognitivo, assim como identificar autores, fundamentos teóricos e teorias que apontem estudos envolvendo o campo da música e a organização do conhecimento. Para tanto, foi realizada uma pesquisa bibliográfica baseando-se em publiçações científicas na área da Música, Linguagem e Semiótica. Por meio dessa pesquisa foi possível compreender que a música apresenta significados subjetivos que estão relacionados ao contexto social e às experiências humanas já vivenciadas. Dessa forma foi possível compreender que as informações musicais estão intimamente relacionadas ao contexto social em que o ser humano está inserido, pois é nele que, por meio do processo cognitivo, se constrói o conhecimento.
\end{abstract}

\section{Palavras-chave}

Semiótica. Música. Organização da Informação.

\section{Abstract}

This study aimed to analyze the informative potential of the field of music from the perspective of the semiotics of Charles Sanders Peirce. Music presents itself as a field of diverse informative possibilities, including documents and data, the phenomenon observed through the experience and the cognitive process, as well as to identify authors, theoretical foundations and theories that point out studies involving the field of music and the organization of knowledge. For this, a bibliographic research was carried out based on scientific publications in the area of Music, Language and Semiotics. Through this research it was possible to understand that music presents subjective meanings that are related to the social context and human experiences already experienced. In this way it was possible to understand that musical information is closely related to the social context in which the human being is inserted, since it is in him that, through the cognitive process, knowledge is constructed

\section{Keywords}

Semiotics. Music. Information Organization. 


\section{INTRODUÇÃO}

A música é uma forma de linguagem que se configura de acordo com o contexto em que é analisada. Os signos resultantes da análise interpretativa da música muito interessa à Semiótica peirceana, que se propõe a estabelecer relações entre significação e significante, compreendendo todas as linguagens. Amparada na Filosofia enquanto ciência, a Semiótica tem como objetivo observar os fenômenos à nossa volta, buscando representá-los por meio dos significados obtidos dessa relação.

Desta forma, a música se revela como um campo com grande potencial informativo, logo rico em possibilidades significativas. Seu potencial informativo pode ser encontrado em forma de documentos e registros, assim como na forma de interpretação, o que a leva ao campo da subjetividade, onde os significados são observados considerando fatores sociais, cognitivos ou outro que se apresente à mente humana.

A música é um campo abrangente e que apresenta além de informações descritivas e documentais, elementos subjetivos, cujos significados estão relacionados ao campo do conhecimento e ao contexto em que está inserido. Cabe, portanto, à Semiótica compreender esses significados resultantes da complexa relação que ocorre entre o homem e os objetos que interpreta.

O objetivo geral desta pesquisa foi identificar as contribuições da Semiótica para a organização da informação no campo da música. Para tanto, como objetivos específicos pretende-se levantar a literatura sobre Semiótica, música e organização do conhecimento; relacionar os temas de estudo mais importantes; identificar os autores e fundamentos teóricos; e sistematizar as teorias que dão suporte aos estudos semióticos aplicados ao campo da música no que tange à organização do conhecimento.

Diante da complexidade que envolve a análise do potencial informativo musical, a Semiótica peirceana se apoia no Falibilismo apontado por Peirce, onde a experiência e o cognitivo não resultam em termos definitivos ou cristalizados da compreensão humana. É nesse sentido que a Semiótica peirceana se apresenta como caminho para observar os fenômenos de todas as linguagens.

O presente artigo foi pautado em pesquisa bibliográfica, baseando-se em publicações científicas na área da Música, Linguagem e Semiótica. Para Gil (2008), a pesquisa bibliográfica é desenvolvida com referências de materiais já elaborados, como livros e publicações científicas. Fachin (2001) destaca a importância da pesquisa bibliográfica como base para as demais pesquisas, se tornando uma atividade que se estenderá na vida de quem se propõe estudar.

Koche (1997, p. 122) afirma que a pesquisa bibliográfica pode ser realizada:
a) para ampliar o grau de conhecimentos em uma determinada área, capacitando o investigador a compreender ou delimitar melhor um problema de pesquisa;
b) para dominar o conhecimento disponível e utilizá-lo como base ou fundamenta- ção na construção de um modelo teórico explicativo de um problema, isto é, como instrumento auxiliar para a construção e fundamentação de hipóteses;
c) para descrever ou sistematizar o estado da arte, daquele momento, pertinente a um determinado tema ou problema.

Percebe-se que esse tipo de pesquisa conduz a investigações já realizadas na área, trazendo respostas para o problema e apontando caminhos para futuras pesquisas.

A presente pesquisa tem como eixo norteador a análise da informação musical por meio da Semiótica peirceana que contempla todas as formas de linguagens e experiências. 
Dessa forma, a Semiótica de Peirce fornece pressupostos para análises dos fenômenos em toda sua complexidade, gerando potencial significativo por meio do processo cognitivo.

O objetivo geral do artigo foi identificar as contribuições da semiótica para a organização da informação no campo da música. Para tanto, necessita-se revisar a base teórica da semiótica e as contribuições ao campo da música.

\section{SEMIÓTICA}

A Semiótica, ciência das linguagens em diferentes contextos, surge como instrumento indispensável para analisar e compreender o signo em todas as suas possibilidades. Contrário ao positivismo de Descartes, a Semiótica peirceana demonstra que os signos são produzidos pela mente humana por meio da experiência e analisados por meio da observação. Esta seção tem como objetivo explicar as diferenças entre Semiótica e Semiologia.

O campo de atuação da Semiótica é amplo, tendo como fundamento a tríade denominada pansemiótica (NOTH, 2005a, p. 62), "ancorada em uma análise das teorias micro e macroscópica do processo de geração, auto-geração e interpretação dos signos (ALMEIDA, 2009, p. 225)". Prates (2003) considera que tudo pode ser semioticamente analisável e classificável fenomenologicamente de acordo com as três categorias: primeiridade, secundidade e terceiridade. Essas categorias concebidas por Peirce permite analisar todos os fenômenos por meio da experiência e da observação dos signos. Cabe, portanto, compreender os interesses e objetivos de cada nicho semiótico e analisar semelhanças e divergências com o intuito de estruturá-las dentro de um campo maior.

O século XX presencia o crescimento de duas ciências da linguagem: uma delas é a ciência que estuda a Linguística, sendo a linguagem verbal sua área de atuação, e a outra a Semiótica, que se propõe a estudar a ciência de todos os tipos de linguagem (SANTAELLA, 2007). Embora essas ciências estivessem ocorrendo no mesmo período, a busca pela compreensão dos signos envolvia interesses ambíguos. Enquanto a Semiologia se limitava a estudar os signos linguísticos, a Semiótica se propunha a analisar todas as experiências humanas no sentido de analisar os signos da relação do homem com o mundo.

O campo da Linguística passou por três momentos históricos, sendo a gramática, a filologia e os neogramáticos (COELHO NETTO, 1980). Nesse contexto, tem-se Saussure, o criador da Semiologia, sendo essa uma ciência geral que norteia a relação entre os homens em todos os sistemas de signos (COELHO NETTO, 1980). As preocupações eram: recuperar textos que estavam caindo no esquecimento (filologia), a gramática, que regulamentava os usos textuais e os neogramáticos, que discutiam as diferentes sonoridades linguísticas de cada região.

Nesse sentido, é importante compreender a diferença que se apresenta entre as linguagens, e, consequentemente, compreender Semiologia e Semiótica como áreas com abrangências que compreendem campos diferentes. Conforme explicado acima, embora abordem campos diferentes, Semiologia e Semiótica possuem em comum o signo, sendo esse um elemento da Linguística (Saussure, Hjelmeslev), ou algo que está no lugar de outra coisa (Peirce) inserido em todas as linguagens (COELHO NETTO, 1980).

Linguagem e mundo se complementam e a Semiótica se apresenta como metodologia capaz de investigar todas as linguagens possíveis, examinando como se constitui todo e qualquer fenômeno onde ocorre a produção de significados e sentidos (SANTAELLA, 2007). $\mathrm{O}$ autor deixa claro que, em todos os sistemas de vidas, é possível encontrar linguagem. Portanto, ela não está presente apenas na escrita ou na fala, mas sim em todos os lugares onde 
houver um olhar e possibilidades de significação e produção de sentidos estiverem presentes.

Os diferentes olhares para a Semiótica vistos no século XX ocorreram em concomitância em três pontos diferentes: Estados Unidos, União Soviética e Europa Ocidental. Santaella (2007, p. 3) afirma ser reflexo da "proliferação histórica crescente das linguagens e códigos, dos meios de reprodução e difusão de informações e mensagens". A autora deixa claro que essa proliferação se iniciou após o início da Revolução Industrial, fazendo emergir uma "consciência semiótica". A Semiótica russa (Hjelmslev, Jakobson, Bakhtin) tinha como eixo temático a cultura; A Semiótica europeia ou Semiótica Estruturalista/Semiologia (Saussure, Barthes, Greimas) tinha seus olhares voltados para a Linguística; já a Semiótica americana (Peirce), buscava compreender a ação do signo em todas as suas possibilidades (COELHO NETTO, 1980).

Se por um lado, Hjelmslev e Saussure se estreitavam a métodos que estivessem estritamente relacionados à Linguística e isento de elementos filosóficos, sociológicos e psicológicos, o modelo semiótico de Peirce buscava exatamente essa direção (COELHO NETTO, 1980). Tratando-se, portanto, de uma Semiótica que seja capaz de dialogar com áreas extralinguísticas, a Semiótica peirceana se distancia das Semiologia buscando significados em experiências do cotidiano.

A música, assim como as artes visuais, por exemplo, são linguagens que produzem significados e sentidos, porém com significados variáveis, de acordo com o nível de interpretante. Como mencionado anteriormente, esse se torna o elemento que reforça a importância da Semiótica peirceana no presente trabalho, onde o signo é reflexo da experiência e observação de toda prática que possa gerar significados.

Comparando as escolas semióticas citadas acima e buscando compreender a visão abrangente de Peirce no que se refere a possibilidades de significação e significante, é preciso introduzir a Semiótica em contextos diferentes dos propostos por Saussure e Hjelmslev, pois:

\footnotetext{
Enquanto neste caso a semiologia apresentava-se como um sistema fechado em si mesmo, "puro", isento daquilo que Hjelmslev designava como "contaminações transcendentais", a semiótica alimentava-se de uma filosofia transcedentalista que vai procurar nos efeitos práticos, presentes ou futuros, o significado de uma proposição, ao invés de ir procurá-los num jogo de relações internas no discurso. (COELHO NETTO, 1980, p. 55).
}

Se, por um lado, Hjelmslev se estreitava a métodos que estivessem estritamente relacionados à Linguística e isento de elementos filosóficos, sociológicos e psicológicos, segundo Coelho Netto (1980, p. 52),

Pode-se dizer que a teoria de Charles Sanders Peirce (nascido em Cambridge, Mass. EUA, em 1839 e morto em 1914) é exatamente oposta à de Hjelmslev na medida em que uma teoria do sentido só pode existir no meio de um corpo filosófico maior - não sendo mesmo inadequado afirmar que a semiótica de Peirce é uma filosofia.

A Semiótica de Peirce, enquanto área da filosofia, se propõe a estudar todas as linguagens, estando aberta a novas possibilidades de sentido e significação. Conforme citado, a Semiótica, enquanto ciência, busca por meio da observação e da experiência mostrar os processos pelos quais se chegou a determinado resultado. Nesse sentido, o autor enfatiza que 
mesmo a filosofia transcedentalista é dotada de significados que podem ser representados pela experiência.

Silveira (2007, p. 23) supõe que:

\begin{abstract}
Entendendo a filosofia como um procedimento científico, e em seu interior a Semiótica, caberá a ela observar o fenômeno que deseja estudar, propor sob a forma de uma figura imaginária, por Peirce denominada Diagrama, um conjunto de relações que espera melhor representar aquele fenômeno e desse modo antecipar como deverá proceder, seguindo passo a passo as indicações contidas na figura, alcançar efetivamente, em seus exemplares concretos, a interação pretendida com o fenômeno.
\end{abstract}

Segundo os autores citados anteriormente, a Semiótica de Peirce permite que por meio da observação e da experiência seja possível obter significados e sentidos, tendo como análise os signos resultantes dessa relação. Como se pode perceber, a inteligência científica se dá por meio da observação e experiência, o que faz da Lógica ou Semiótica instrumento de análise nas pesquisas que se pretende. A Semiótica é uma ciência rigorosa, construtora de formas ideais, pelas quais por via dedutiva e, portanto, a modo de necessidade, demonstrará suas conclusões (SILVEIRA, 2007).

Pode-se dizer que, a Lógica ou Semiótica, é uma via de possibilidades que por meio de pressupostos científicos pode gerar significados. Nesse sentido, cabe, por meio de análises, compreender os signos resultantes dessas relações através dos estudos propostos por Peirce em sua busca por compreender o signo e suas relações. O processo de interpretação dos signos supõe que "signo é aquilo que representa alguma coisa para alguém sob algum aspecto, em nada interessando se há ou não intenção, no signo, em comunicar ou oferecerse à interpretação" (COELHO NETTO, 1980, p. 42). Para ilustrar o entendimento, pode-se, por exemplo, citar a análise do tempo em comunidades interioranas por meio da observação das nuvens ou outro elemento da natureza, como círculos ao entorno da lua, indicando chuva ou ausência dela etc.

Dessa forma, pode-se compreender que, ao contrário da Matemática, que pressupõe resultados exatos, a Semiótica nos remete a possibilidades significativas que nos remete a análises para sua compreensão. Deste modo, pode-se compreender, segundo Silveira (2007), que, no caso da Semiótica, diferentemente da Matemática, mesmo em sua função lógica, tem-se uma ciência positiva, no sentido em que seu objeto não é meramente uma construção ideal, mas um fato complexo a ser observado e do qual, por via de abstração, deve-se construir um diagrama que represente aquelas relações essenciais para sua compreensão.

Pode-se compreender, portanto, que a aprendizagem por meio da experiência é estabelecida pela Semiótica, através dos signos que resultam dessa relação. Da relação entre o homem e os objetos surgem os signos, independente desse signo comunicar ou oferecer-se a interpretações. Dessa forma, compreender os signos e os significados que resultam das relações por ele estabelecidas se tornam pressupostos para nossa compreensão de Semiótica.

Analisando a obra de Peirce, a partir do ponto de vista histórico, é possível perceber que sua base transitava entre o idealismo e o realismo. Para Ibri (1992, p.128), "O idealismo peirceano assemelha-se ao de Platão pela sua objetividade e não ao matiz subjetivo do idealismo de Berkeley [...] cumpre recordar, também, que o realismo de Peirce é escolástico, ou seja, estruturados nos atributos da generalidade e alteridade".

Por realismo, pode-se entender a observação da experiência cotidiana em busca da verdade (IBRI, 1992). Nesse sentido, para Peirce "a experiência é o inteiro resultado cogniti- 
vo do viver." (PEIRCE, CP 7, 527 apud IBRI 1992). A busca pela compreensão da realidade por Peirce se apoia no Falibismo, "pois se a experiência é o resultado cognitivo do viver, este mesmo viver é moldado por elaborações cognitivas que não alcançam um termo definitivo e cristalizado, pois falível." (MEDEIROS, 2009, p. 58). Este é, portanto, o caminho da Semiótica onde manifestações de todas as linguagens podem ser observadas.

Se para Kant havia um limite para o conhecimento, para Peirce esse caminho deveria ser livre. Em contraposição ao positivismo preestabelecido, Peirce apontava para a busca da investigação do fenômeno em todas as linguagens (SANTAELLA, 2007). Nesse sentido, classifica a ciência em três desdobramentos, sendo: I) Fenomenologia; II) Ciências Normativas (Estética, Ética e Lógica) e III) Metafísica (SANTAELLA, 2007, p. 6). A Semiótica ou Lógica se encontra dentro do campo das Ciências Normativas, sendo que a Fenomenologia abrange suas três áreas: a Estética, a Ética e a Lógica (ou Semiótica).

Para Peirce, faneron (ou fenômeno) "[...] é tudo que está na mente, real ou não" (IBRI, 1992, p. 4). Nesse sentido, compreende-se que Fenomenologia está presente no cotidiano, em todas as experiências que acontecem a todo instante e deve, portanto, ser observada a partir das categorias fenomenológicas estabelecidas por Peirce, que são: primeiridade, secundidade e terceiridade. A partir dessas categorias, os signos serão analisados também em outras três tricotomias (signo com ele mesmo, signo com o objeto e signo com o interpretante) estabelecendo assim uma relação triádica.

As três categorias peirceanas referem-se aos níveis em que o signo revela os fenômenos contidos nas relações de tricotomia descritos anteriormente. Para Santaella (2007, p. 9), "Essas três categorias irão para o que poderíamos chamar três modalidades possíveis de apreensão de todo e qualquer fenômeno. [...] Elas se constituem [...] nas modalidades mais universais e mais gerais, através das quais se opera a apreensão-tradução dos fenômenos."

Para Coelho Netto (1980, p. 61) "A primeiridade recobre o nível do sensível e do qualitativo, e abrange o ícone, qualissigno e rema". A primeiridade é o nível onde as qualidades se apresentam e ainda não foram sujeitas a análises, estando ainda no universo das possibilidades, do que ainda irá se revelar ao pensamento, do imediato e do instante presente.

Santaella (2007, p. 9) discorre que a primeiridade:

Trata-se, pois, de uma consciência imediata tal qual é. Nenhuma outra coisa senão pura qualidade de ser e de sentir. A qualidade da consciência imediata é uma impressão (sentimento) in totum, indivisível, não analisável, inocente e frágil. Tudo que está imediatamente presente à consciência de alguém é tudo aquilo que está na sua mente no instante presente.

Segundo a autora, a primeiridade é a qualidade do imediato, do sentimento, pois a partir do momento que se pensa já deixa de estar em primeiridade, pois surgem dessa relação novos significados, fruto do pensamento, da negação do primeiro e da análise. A primeiridade sendo imediata precedendo o pensar é como o fenômeno nos aparece de forma indeterminada, original e vaga (SANTAELLA, 2007).

A secundidade, por sua vez, diz respeito ao nível da experiência, da coisa ou do evento: é o caso do índice, do sinsigno e do dicissigno (COELHO NETTO, 1980, p. 61). Nesse nível o signo se revela por meio da prática, do concreto que representa o Objeto através da qualidade que a ele se remete. Para Santaella (2007, p. 10), porém, “[...] a qualidade é apenas uma parte do fenômeno, visto que, para existir, a qualidade tem de estar encarnada numa matéria". A existência da qualidade caracteriza a secundidade pelo fato dessa estar materializada e ser analisada por meio da experiência. 
A terceiridade "refere-se à mente, ao pensamento, isto é, à razão: cobre o campo do símbolo, do legissigno e do argumento" (COELHO NETTO, 1980, p. 61). Esse é o nível mais profundo da representação, isto é, os signos de convenção em nossa relação com o mundo. Para Ibri (1992, p 13), "Mediar é uma experiência sintetizadora, característica da terceiridade, onde a primeiridade e secundidade se fundem por meio do intelecto, da relação do homem com mundo, por meio do pensamento". A "terceiridade, que aproxima um primeiro e um segundo numa síntese intelectual, corresponde à camada de inteligibilidade, ou pensamento em signos, através da qual representamos e interpretamos o mundo." (SANTAELLA, 2007, p. 11). Sabe-se, pois que, os signos estão presentes em tudo, possibilitando e estabelecendo relações. Segundo Peirce (1975, p. 56), "Um signo ou representamem, é algo que, sob certo aspecto ou de algum modo, representa alguma coisa para alguém". Fica claro que para que um signo se configure é preciso que ele represente algo, que nessa relação se torna seu objeto. O signo resultante dessa relação é, portanto, dotado de significação e sentido.

Para Santaella (2007), um signo intenta essa representação, porém, para que isso realmente ocorra, é preciso que haja uma mente afetada, resultando em um terceiro, seu interpretante. Nesse sentido, nota-se que há, portanto, uma relação triádica, onde o objeto media o Interpretante por meio de um signo. Para Almeida (2009, p. 227):

\footnotetext{
O signo, sendo um primeiro, possui qualidades semelhantes às presentes no objeto que representa, o objeto que determina o signo é representado pelo signo por alguns elementos pertinentes também nele, as qualidades. O signo determinado pelo objeto impele a existência e ao desenvolvimento de um terceiro elemento que é o interpretante do signo.
}

De acordo com a citação acima, tudo que afeta a mente de um terceiro, ou seja, seu interpretante, resulta em um signo. Nesse sentido, nota-se que o signo estabelece relações consigo mesmo, com o Objeto e com o Interpretante em três níveis estabelecidos por Peirce em primeiridade, secundidade e terceiridade. Subentende-se, portanto, que o signo representa seu Objeto gerando sentido e significados.

Se para a Semiologia o que interessa é saber como ocorre o processo de interpretação do signo e mensurar ou compreender a ação do signo sobre o receptor ou intérprete (COELHO NETTO, 1980), para a Semiótica, o "signo representa alguma coisa para alguém sob algum aspecto, em nada interessando se há ou não intenção, no signo, em comunicar ou oferecer-se à interpretação" (COELHO NETTO, 1980, p. 45). O autor deixa claro que a dimensão a qual a Semiótica se propõe nas relações triádicas supera as possibilidades estabelecidas pela Semiologia.

Percebe-se que um signo estabelece relações complexas, não se limitando a um jogo rígido e inflexível. Nesse sentido, nota-se que "o signo não é uma coisa monolítica, mas um complexo de relações" (SANTAELLA, 2007, p. 13). O autor aponta que é preciso compreender e classificar os signos a partir das relações de complexidade que ele estabelece. $\mathrm{Na}$ Semiologia o signo se encontra dentro de uma relação de fala e escrita, enquanto a Semiótica possibilita análise de significação em situações mais complexas, como por exemplo, na análise de obras de arte, músicas e outras experiências em que o fenômeno esteja presente. Dessa forma, percebe-se que o significado não se encontra preso ao objeto, mas nas relações que este estabelece consigo mesmo e também com seu Interpretante. Conforme explicado acima, a Semiótica, sendo uma ciência voltada aos fenômenos, busca por meio do confronto de hipóteses explicar o que objeto que se propõe analisar. 
Para Santaella (2007, p. 18), "Não há dúvida que a linguagem tem sido, neste século, o objeto nuclear das indagações filosóficas". Não se intenta nesse diálogo desmerecer a importância da Semiologia e muito menos reduzir sua importância, mas compreender sua importância dentro de uma Semiótica Geral, sabendo que fenômenos mais complexos exigem novas abordagens e experiências. Percebe-se, portanto que, a Semiótica peirceana se propõe a analisar tais fenômenos, possibilitando e gerando significados fora do campo da Linguística.

Embora em sua obra Peirce tenha proposto a existência de dez tricotomias e sessenta e seis classes de signos, abordar-se-ão neste artigo apenas três tricotomias e dez classes. Segundo Coelho Netto (1983, p. 57), "isso se deve ao fato de se apresentarem como suficientes para uma análise semiótica e as demais tricotomias e classes não serem suficientemente detalhadas por Peirce".

Antes de adentrar às tricotomias estabelecidas por Peirce, é importante discorrer sobre a visão de Peirce no que se refere à capacidade cognitiva do homem em suas relações com o mundo. Contrário a Descartes, que acreditava que o conhecimento se dava pela intuição, Peirce acreditava que o processo cognitivo depende dos signos, assim como os pensamentos (COELHO NETTO, 1983). Para o autor, o conhecimento acontece por meio da inferência, da observação e das hipóteses extraídas nessa relação.

Embora Peirce não qualificasse sua filosofia como antropocêntrica, pode-se hoje considerá-la assim, ou seja, um signo pode ser encontrado em qualquer lugar da natureza e a secundidade é resultante das qualidades que se encontram na primeiridade, tornando-se lei num processo de representação da experiência (ALMEIDA, 2009).

Partindo do pressuposto de que o signo mantém uma relação triádica com o Objeto e com o Interpretante, cabe aqui abordar esses dois elementos da teoria de Peirce. Sabendo que o signo se encontra em primeiridade, tendo o Objeto em secundidade e o Interpretante em terceiridade, deve-se aqui reconhecer o que difere um e outro, e quais relações estabelecem entre si. Sendo o signo o primeiro, o objeto estando em secundidade carrega em si elementos do signo. Para Almeida (2009, p. 235), "o objeto é um segundo, isto significa falar que o objeto possui elementos encontrados na segunda categoria fenomenológica". Esses elementos da primeiridade encontrados no objeto são, portanto, representações do mesmo, que serão interpretadas por um terceiro. O Objeto pode ou não ser uma coisa, podendo ser um evento ou fenômeno imaginado em secundidade (ALMEIDA, 2009).

Para Peirce, o Objeto se divide em objeto dinâmico e objeto imediato, sendo o objeto dinâmico o objeto em si e o objeto imediato uma suposta representação do objeto. Ao objeto enquanto contido no signo a que se refere, Peirce denomina Objeto Imediato do signo. Ao objeto enquanto só alcançável por experiência colateral, Peirce denomina Objeto dinâmico do signo (SILVEIRA, 2007, p.46).

No que se refere ao Interpretante, Peirce o divide em dois grupos, sendo o primeiro grupo composto por interpretante imediato, interpretante dinâmico e interpretante final, e segundo grupo, por interpretante emocional, interpretante energético e interpretante lógico.

No primeiro grupo, segundo Santaella (2005, p. 47), “o interpretante imediato é uma propriedade objetiva do Signo para significar, que advém de seu fundamento, de um caráter que lhe é próprio". Já o interpretante dinâmico, "se refere ao efeito efetivamente produzido em um intérprete pelo signo" (SANTAELLA, 2002, p. 129). Por fim, o interpretante final que:

[...] se refere ao resultado interpretativo a que todo intérprete estaria destinado a chegar se os interpretantes dinâmicos do signo fossem levados até o seu limite úl- 
timo. Como isso não é jamais possível, o interpretante final é um limite pensável, mas nunca inteiramente atingível. (SANTAELLA, 2002, p. 26).

Como se pode notar, o interpretante imediato está relacionado ao signo, enquanto o interpretante dinâmico ao efeito produzido pelo signo no interpretante, e o interpretante final, ao aprofundamento dessa relação signo-interpretante quando levada a interpretações mais profundas.

No segundo grupo, tem-se o interpretante emocional que "é o primeiro efeito semiótico, em termos de qualidade, portanto, qualidade de sentimento, de um signo (SANTAELLA, 2000 , p. 78). Já o interpretante energético corresponderia a uma reação da mente interpretante, que pode ser uma reação muscular, a manipulação de algum objeto no mundo exterior ou "esforços interiores, atos de imaginação" (SANTAELLA, 1995, p. 105). O interpretante lógico, por sua vez, "é o pensamento ou entendimento geral produzido pelo signo" (SANTAELLA, 1995, p. 105).

Sabe-se, pois, que o signo mantém uma relação triádica consigo mesmo, com seu objeto e com seu interpretante, ora representando elementos do signo, ora apresentandose como coisa em relação ao signo ou conceituando ou convencionando a relação entre signo e objeto.

Como visto anteriormente, a teoria dos signos de Peirce busca em suas relações triádicas atender todas às áreas de ciência em que ocorra conceitos sígnicos tão gerais que pudessem servir de alicerce a qualquer ciência aplicada. O propósito de Peirce com sua teoria não era substituir outras ciências e sim contribuir no que se refere à linguagem, dentro de uma perspectiva onde a Lógica seja o fundamento que a sustente (ALMEIDA, 2009). Dessa forma, Peirce estabeleceu uma divisão triádica onde o signo se relaciona consigo mesmo, com seu Objeto e com seu interpretante, conforme ilustrado no Quadro 1.

Quadro 1 - Modos categóricos dos signos peirceanos

\begin{tabular}{||c||c|c|c|}
\hline \multirow{2}{*}{ CATEGORIAS } & \multicolumn{3}{c|}{ TRICOTOMIAS } \\
\cline { 2 - 4 } & \multicolumn{1}{|c|}{ SIGNO I } & \multicolumn{1}{c|}{ SIGNO II } & \multicolumn{1}{c|}{ SIGNO II } \\
\cline { 2 - 4 } & $\begin{array}{c}\text { REPRESENTAMEN } \\
\text { EM SI }\end{array}$ & $\begin{array}{c}\text { RELAÇÃO AO } \\
\text { OBJETO }\end{array}$ & $\begin{array}{c}\text { RELAÇÃO AO } \\
\text { INTERPRETANTE }\end{array}$ \\
\hline \hline PRIMEIRIDADE-1 & QUALI-SIGNO & ÍCONE & REMA \\
\hline \hline SECUNDIDADE-2 & SIN-SIGNO & ÍNDICE & DICENTE \\
\hline \hline TERCEIRIDADE-3 & LEGI-SIGNO & SÍMBOLO & ARGUMENTO \\
\hline \hline
\end{tabular}

Fonte: Nöth (2009).

Embora há quem prefira iniciar os estudos das relações triádicas a partir da relação signo com seu Objeto (COELHO NETTO, 1980), a primeira relação apresentada por Peirce é a do signo consigo mesmo, certamente por se apresentar em primeiridade. Nesse sentido, o signo se relaciona consigo mesmo, onde em primeiridade ele apresenta qualidades de um signo, em secundidade, a singularidade de um signo e em terceiridade, o signo convencionado, sob as condições de lei. Dessa forma, entende-se que:

Quali-signo é uma qualidade que é um signo.

Um Sin-signo (onde a sílaba sin significa "uma única vez", como em "singular", "simples", no latim semel, etc) é uma coisa existente ou acontecimento real, que é um signo.

Um Legi-signo é uma lei que é um signo. Tal lei é comumente estabelecida por homens. (COLEHO NETTO, 1980, p. 60-61) 
Na primeira tricotomia o signo apresenta as qualidades que são em sin-signos. "Um sinsigno é uma coisa ou evento existentes, tomados como signo (COELHO NETTO, 1980, p. 60). Conforme mencionado, a qualidade está para o universo fenomênico, onde em si mesma preceda a existência (COELHO NETTO, 2007).

A segunda tricotomia se refere à relação do signo com o Objeto, obedecendo os níveis de primeiridade, secundidade e terceiridade. Nesta tricotomia, os signos representam o Objeto, referindo-se ao mesmo através do Ícone, do Índice e do Símbolo, respectivamente.

Para Peirce (1980, p, 101), "um Ícone é um signo que se refere ao Objeto que denota simplesmente por força de caracteres próprios e que ele possuiria, da mesma forma, existisse ou não efetivamente um Objeto daquele signo". Nota-se que em primeiridade um ícone carrega em si qualidades que representam o Objeto, como por exemplo o desenho de uma casa ou uma fotografia.

Em secundidade, o signo se relaciona com seu Objeto por meio do Índice, indicando qualidades que o representam de fato, ao ser afetado por ele; "Índice é um signo que se refere ao objeto denotado em virtude de ser diretamente afetado por esse objeto" (COELHO NETTO,1980, p. 58).

O Símbolo encerra a segunda tricotomia por meio da convenção do Símbolo, que passa a representar o Objeto por força de lei estabelecida pelos usuários. "Um Símbolo é um signo que se refere ao Objeto que denota por força de uma lei, geralmente uma associação de idéias gerais que opera no sentido de elevar o Símbolo a ser interpretado como se referindo àquele Objeto" (PEIRCE, 1980, p. 102). Nota-se nessa tricotomia que a representação do Objeto é sua característica principal, gerando significação e sentido que remetem ao Objeto ao representá-lo.

A última tricotomia peirceana trata da relação entre o Signo e seu Interpretante por meio da emoção, do pensamento e da consciência. Segundo Peirce (apud SILVEIRA, 2007, p. 49), [...] "o pensamento é um meio para se alcançar o Objeto que se deseja".

Em primeiridade, na relação Signo/Interpretante tem-se o Rema, que de acordo com Peirce (1980, p. 102), é um Signo que, para seu Interpretante, é um Signo de Possibilidade qualitativa, ou seja, entendido como representando tal e tal espécie de Objeto possível. 0 Rema, por estar em primeiridade e possuir qualidades representativas do signo, pode gerar possibilidades interpretativas (SILVEIRA, 2007).

O segundo nível dessa terceira tricotomia refere-se ao Dicissigno, que é um Signo que, para seu Interpretante, é Signo de existência concreta (Peirce). Indica de fato qualidades que se referem diretamente ao Objeto por meio da interpretação, do pensamento etc. 0 Argumento é o último nível da relação do signo com o Interpretante. Para Peirce (1980, p. 102), "um Argumento é um Signo que, para seu Interpretante, é um Signo de lei".

O Interpretante é para a Teoria dos Signos de Peirce peça fundamental para a compreensão do universo complexo em que se insere o Signo. É o terceiro de uma relação triádica genuína, onde no jogo dessas relações assume a mesma relação com seu Objeto, sendo capaz de determinar um terceiro que lhe seja próprio (SANTAELLA, 2000). Nota-se nesse sentido, a importância da relação Objeto/Interpretante no processo de definição do signo. Tal importância se deve ao fato de considerar o Signo indeterminado em si mesmo, desenrolando-se através dos processos interpretativos.

$\mathrm{O}$ ato de interpretar pode muitas das vezes ser particular ou individual, dependendo do nível de abstração em que cada interpretante se encontra no processo de produção dos signos. Nesse jogo de relações, segundo Santaella (2000), o Signo representa o Objeto, ge- 
rando o Interpretante ao afetar uma mente (existente ou potencial). Nesse sentido, o Interpretante também se faz Signo, que constituirá num outro signo sucessivamente.

Dentro da relação triádica genuína em que o Interpretante se encontra é ele também um Signo, pois pode ser também representado. Para melhor compreensão dessa relação triádica dentro do processo de significação é preciso analisar a classificação dos interpretantes. Para Santaella (2000), a divisão dos interpretantes em imediato, dinâmico e final foi bastante tardia, aparecendo apenas em 1904, quando Peirce passou a se dedicar à tricotomia do interpretante.

Não se prendendo a fatos históricos e evolutivos de como se deu a tricotomia do interpretante e buscando de fato analisar sob um ponto de vista já definido sobre a questão, onde a primeira classificação do interpretante ficou definida dentro de uma relação genuína como: imediato, dinâmico e final. Tomar-se-á como exemplo o modelo mais conhecido, originado por volta de 1904 e tendo como a Fenomenologia ou teoria das categorias triádicas (SANTAELLA, 2000).

Para Santaella (2002, p.37), "é só na relação com o interpretante que o signo completa sua ação como signo. É apenas nesse ponto que ele age efetivamente como signo". Nesse sentido, o interpretante imediato se refere ao que o signo tem potencial latente, ou seja, aquilo que é expresso de imediato. Aqui o signo é compreendido como possibilidade, embora ainda abstrata, contida no próprio signo e ainda isento de análise ou mediação (SANTAELLA, 2000).

O interpretante dinâmico, por sua vez "se refere ao efeito efetivamente produzido em um intérprete pelo signo" (SANTAELLA, 2002, p. 129). Uma das qualidades da secundidade se refere ao signo na prática, na vivência ou experimentação. É o momento em que o signo se concretiza de fato, onde o signo é apreendido empiricamente (SANTAELLA, 2000).

Já o interpretante final refere-se ao resultado interpretativo que o interpretante é capaz de levar o signo.

Extraída das três categorias, a segunda tricotomia apareceu por volta de 1907, segundo Santaella (2000), e foi formulada em: interpretante emocional, energético e lógico.

O interpretante emocional "é o primeiro efeito semiótico, em termos de qualidade, portanto, qualidade de sentimento, de um signo" (SANTAELLA, 2000, p. 78). Compreende-se, nesse sentido, que o signo em primeiridade é ainda um signo a ser analisado, traduzido, porém dotado de valores emocionais.

O interpretante energético, na qualidade de secundidade, é um signo vivenciado de alguma forma. Nesse caso, há um despendimento de energia que o qualifica dessa maneira. O interpretante energético, sendo uma ação, "supõe um tono de sentimento que o sustente e que, pelo confronto com sentimentos opostos, o determine" (SILVEIRA, 2007, p. 52-53).

No que se refere ao Interpretante lógico, é o interpretante que em sua função terceira nas categorias de Peirce exerce a função de apreender intelectualmente um signo, convencionando-o por meio de regras estabelecidas. O interpretante lógico, por sua vez, é definido como o pensamento ou entendimento geral produzido pelo signo, ou ainda, como uma "regra geral, que não se confunde com um conjunto de palavras, mas é mais propriamente um hábito de ação que pode ser expresso por palavras" (SANTAELLA, 2000, p.79).

A Semiótica de Peirce é uma área da Filosofia que permite analisar o signo independente da linguagem que ele esteja inserido. A música por ser uma linguagem e estar intimamente relacionado ao contexto em que é produzida está sujeita ao Falibilismo citado por Peirce, onde o significado está sujeito a interpretações, pois é por meio do processo cognitivo e embasado em informações anteriores que o conhecimento é construído. 


\section{MÚSICA, INFORMAÇÃO MUSICAL E REPRESENTAÇÃO DA INFORMAÇÃO EM MÚSICA}

A música é um fenômeno complexo que abrange as várias dimensões da experiência humana. Essas dimensões, por sua vez, podem ser objetivas ou subjetivas, podendo ser compreendidas numa mesma dimensão entre os pares ou de uma forma mais abrangente e singular de acordo com a compreensão de cada grupo social. Para Queiróz (2000, p. 19), "a música utiliza-se da relação sensorial [...] e quanto mais verdadeiro e significativo o que transmitir, e quanto mais simpaticamente atingir a sensorialidade humana, maior será a Arte". Nesse sentido, é possível compreender que assim como o homem está para a música, a música está para o homem nas experiências sonoras que vivencia, evidenciando a complexidade que a música abrange na experiência humana.

A música é uma manifestação social que está presente nos mais diversos contextos sociais. Desde o nascimento, quando o choro representa a vida que se inicia, nos mais diversos momentos em que a vida nos permite celebrar cada conquista ou até mesmo no momento em que tudo se encerra e a música representa sua função social de fechar as cortinas da vida. Ao mergulhar-se nesse universo de possibilidades que a música apresenta, deparase com paisagens sonoras compostas pelas mais diversas nuances, onde texturas, linhas melódicas, combinações rítmicas e uma infinidade de timbres, alturas, intensidades e contornos se misturam compondo canções que nem sempre se percebe. Para Moraes (1983, p. 7), "[...] tudo pode ser música: o movimento mudo das constelações em contínua expansão, a escola que passa sambando, um jogo, o pulsar cadenciado do coração seu ou alheio, um rito, um grito, o canto coletivo que dá mais força ao trabalho".

Para Barros (2012, p. 15), "a música está presente em quase todas as esferas da vivência humana, é um elemento cultural e, dessa forma, tem seu alicerce nas relações sociais". Utiliza-se a música nos mais diversos contextos do cotidiano. Serve-se da música para o trabalho, para os momentos de alegria ou tristeza, para o lazer, culto religioso e nas mais diversas formas de representação humana.

Moraes (1989) destaca que a música é produzida pelos seres humanos e para os seres humanos, se manifestando de diferentes maneiras, de acordo com a cultura de cada povo. $O$ fato de a música se manifestar de diferentes maneiras e de acordo com a cultura de cada povo, faz com que ela não seja uma linguagem universal, porém, não deixa de ser um fenômeno universal.

Para que os elementos do som possam ser intimamente decodificados é preciso que haja antes disso a escuta. A consciência sonora parte como princípio básico para a organização dos sons para que posteriormente possam ser estruturados de forma criativa. $O$ processo de escuta em si é uma forma de estruturação musical das quais fazem parte os elementos do som estudados na música.

Para se entender a essência do som é preciso entender sua diversidade e complexidade por meio da escuta e classificação. Esse processo de compreensão dos elementos do som nos leva a um nível de interpretação mais consciente e direcionado. Esse processo de tomada de consciência em relação aos sons a nossa volta é chamado de limpeza dos ouvidos (SCHAFFER, 1991). O som passa primeiramente por um processo de escuta, análise e imitação, para em seguida ser treinado auditivamente (PARENTE, 2008).

A percepção musical é uma habilidade que nos leva aos níveis de interpretantes a que Peirce se refere no estudo da Semiótica. Portanto, para que se possa analisar essa diversidade musical e sonora que nos apresenta, é preciso compreender o que é música e qual a matéria prima que a compõe. $O$ universo é repleto de sons e faz-se uso deles no cotidiano 
como forma de representação e significação. A buzina de um carro chamando a atenção ou de um navio anunciando sua partida, a sirene de uma ambulância que pede passagem no trânsito ou da fábrica anunciando o fim do expediente são exemplos das possibilidades significativas do som. $\mathrm{O}$ universo sonoro é rico em significados e representatividade, da qual o homem faz uso em seus mais diversos contextos, como nos exemplos acima.

Para Barros (2012, p. 15), “[...] informação é um elemento manifestado socialmente e dependente do contexto social". Como visto anteriormente, a música é uma manifestação social, logo contém informações que estão ligadas a determinados contextos. Para a Ciência da Informação,

[...] a música é um elemento que carrega possibilidades significativas e, portanto, potencial informativo, tornando-se "informação musical", uma vez que é entendida como recurso informacional passível de ser inserido em um sistema de recuperação da informação para atender às necessidades de diferentes tipos de usuários. (BARROS, 2017, p. 15).

Cabe, portanto, buscar, observar e compreender o perfil dos usuários a quem a informação interessa, considerando todos os aspectos anteriormente citados, como finalidades, interesses e necessidades. Cotta (1998) aponta três tipos de usuários da música de acordo com esses parâmetros: a) o que procura a música como lazer; b) aquele que tem a música como atividade profissional; c) e o que busca a música como objeto de pesquisa.

Para Barros (2017, p. 83), "[...] a literatura sobre informação musical se desenvolve especialmente na área chamada Music Information Retrieval (MIR)", tendo como característica a multidisciplinaridade enquanto área de pesquisa (DOWNIE, 2004). Para McLane (1996), o som é o principal atributo da informação musical, tornando-a diferente dos demais tipos de informação. Bräscher e Café (2010) consideram que "a informação é o registro documentado pronto para ser socializado". Nesse sentido, pode-se dizer que, além de documentos musicais como livros, partituras, discos e demais suportes físicos, o som é, portanto, um elemento que contém informação musical.

Tratando-se do som como elemento característico da informação musical, é importante conhecer o perfil dos usuários, pois, além dos aspectos históricos e sociais, os elementos sonoros e composicionais fazem com que se reforcem a atenção ao usuário, com a finalidade de compreender o fenômeno musical nos diferentes contextos.

A informação musical em meio ao grande avanço dos recursos tecnológicos surge como ferramenta indispensável no que se refere à recuperação da informação via Web. Para Barreto (1998, p. 122), a Ciência da Informação teria como objetivo “[...] criar condições para a reunião da informação institucionalizada, sua distribuição adequada para um público que, ao julgar sua relevância, a valorize para uso com o intuito de semear o desenvolvimento do indivíduo e dos espaços que este habita".

Os metadados "são conjuntos de padrões contendo regras que governam as funções de comunicação num ambiente de rede" (SAYÃO, 2007, p. 19). As funções dos metadados são organizar, preservar, fornecer, padronizar por meio de palavras chaves a informação que se deseja alcançar. Os metadados de certa forma representam a informação por meio de descrições associadas a algum documento.

A "representação da informação é o processo de descrever uma fonte substituindo-a por tal descrição, para fins de recuperação" (BARROS, 2012, p. 58). Segundo Barreto (1998, p.122), "o propósito da Ciência da Informação é conhecer e fazer acontecer o sutil fenômeno da percepção da informação pela consciência [...]". 
Barros (2012) destaca a importância de buscar na literatura características da música para desenvolver um conjunto de metadados que representem a informação musical. Dessa forma, os metadados se apresentam como elementos de extrema relevância no que se refere à representação e recuperação da informação.

Para se compreender e analisar a informação musical é preciso antes entender o que é informação, como ela surge e quais elementos envolve. A informação se manifesta socialmente e depende do contexto social em que ocorre, sendo um processo construtivo que envolve elementos que se relacionam e se manifestam através da percepção sensível (BARROS, 2017). É importante entender que, assim como a música, a informação também é um elemento construído socialmente, com finalidades e significações diferentes de acordo com cada contexto.

Para Barros (2017), a música é rica em possibilidades significativas, o que interessa de fato à Ciência da Informação, uma vez que, por ser um recurso informacional, pode ser inserido em um sistema de recuperação da informação atendendo aos diferentes perfis de usuários. Dessa forma, é possível entender que, embora as informações sejam subjetivas, de alguma forma está relacionada a um determinado contexto e, portanto, interessa a algum tipo de usuário.

Considerando a informação como resultado das relações sociais nos mais diversos contextos e que esta ocorre através da percepção, cabe agora compreender quais as possibilidades informativas que a música oferece para pesquisas. É de fato abrangente o potencial informativo que a música oferece. Embora suas informações tenham registros palpáveis, tanto o processo de interpretação e de compreensão do objeto escrito são subjetivos, sendo interpretados ou compreendidos de maneiras distintas de acordo com o contexto social ou nível de interpretante. Conforme explicitado, o que a percepção sensível capta está relacionada às relações que ocorrem em cada contexto.

Se a informação está vinculada ao contexto, ao ponto de vista histórico e também antropológico, não há o que assegura a objetividade da informação. Mesmo os significados mais subjetivos, como os emocionais, segundo Cumming (2000, p. 69), "são informativos sobre um modo de entendimento". O autor nos leva a pensar que a informação está vinculada ao contexto social, portanto, o significado convencionado em um grupo social não é necessariamente o mesmo de outra cultura ou grupo social.

É importante compreender que a informação musical enquanto produto da percepção sensível está vinculado ao meio em que está inserido, sendo resultado das relações que ocorrem nesse meio. Peirce (1975) aponta que nenhum conhecimento é em si estável e terminado, estando vinculados a aproximações que se dão por meio das experiências. Nesse sentido, a análise da informação musical tem como objetivo explorar todas as potencialidades existentes nos mais diversos contextos. Cabe, portanto, explorar todas possibilidades que a música oferece enquanto potencial informativo. Embora se prese pelas informações objetivas, a subjetividade da interpretação e da decodificação dos documentos musicais devem ser considerados, visto que a informação é fruto da percepção, portando produto da subjetividade.

Barros (2017) busca analisar as informações musicais no campo da organização do conhecimento e da informação, tomando como perspectiva a Semiótica peirceana, uma vez que a Fenomenologia analisa toda e qualquer experiência. No que concerne ao significado dessas experiências, adentra-se na teoria da Semiótica, que se sustenta como fundamento para a construção de uma base teórica sobre informação musical para a área de Organização do Conhecimento e da Informação. 
Portanto, os significados musicais pertencem estritamente a um coletivismo, sendo esse coletivismo resultado de um processo histórico, onde simbologias e significados são convencionalmente construídos. Tais embasamentos nos levam a entender que a música é uma linguagem que possui significados que são criados dentro de um contexto onde a parte está para o todo representado pelo fenômeno musical.

Para Barros (2017, p. 93), o problema que decorre dessa flutuação da música em diferentes esferas se revela na tarefa de mapear seu domínio para definir os conceitos que o compõem e estabelecer suas relações. Barros (2012) aponta algumas características da informação musical como relevantes de acordo com os usuários, como a Musicologia/Etnomusicologia, a Criação Musical, as Práticas Interpretativas e a Educação Musical.

\section{CONSIDERAÇÕES FINAIS}

Sobre como apresentar as potencialidades das informações musicais, Barros (2017, p. 83) aponta duas linhas, onde: "A primeira apresenta abordagens de cunho teórico, que exploram as características da música como informação. A segunda parte apresenta estudos sobre uso e usuários da informação musical, que incluem também os sistemas de recuperação da informação dedicados à música".

Para Barros (2012, p. 117),

[...] a Linguística e a Semiótica podem auxiliar no entendimento dos elementos que circundam a organização do conhecimento e da informação no âmbito da Música, na interpretação e relação de signos - linguísticos ou não - bem como na escolha das estratégias de fixação do significado na tradução da linguagem natural para a linguagem documentária.

Conclui-se, portanto, que a Representação da Informação e a Recuperação da Informação têm como objetivo facilitar as necessidades de buscas dos usuários. Nesse sentido, é importante compreender que tanto a recuperação quanto a representação são fundamentais na gestão da informação (BARROS, 2012).

Dessa forma, conclui-se que, por meio das informações contidas na música de um determinado período, é possível analisar e chegar a informações extramusicais como, por exemplo, as músicas compostas no período do regime militar, cujas letras revelam acontecimentos ocorridos naquele período.

\section{REFERÊNCIAS}

ALMEIDA, C.C. Peirce e a Organização da Informação: contribuições teóricas da Semiótica e do Pragmatismo. Tese (Doutorado em Ciência da Informação), Faculdade de Filosofia e Ciências, UNESP, Marília-SP. 2009.

BARRETO, A. A. Mudança estrutural no fluxo do conhecimento: a comunicação eletrônica. Ciência da Informação, Brasília, v.27, n.2, p.122-127, maio/ago. 1998. Disponível em: http://revista.ibict.br/ciinf/article/view/792/822. Acesso em: 15 out. 2018.

BARROS, C. M. de. Recuperação da informação musical: subsídios para recuperação da informação em registros sonoros e partituras em contexto educacional e de pesquisa. Dissertação (Mestrado em Ciência da Informação) - Universidade Federal de Santa Catarina, Cen- 
tro de Ciências da Educação. Programa de Pós-Graduação em Ciência da Informação. Florianópolis, SC, 2012.

COELHO NETTO. J. T. Semiótica, informação e comunicação: diagrama da teoria do signo. São Paulo: Editora Perspectiva, 1980.

COELHO NETTO, J. T. Semiótica, informação e comunicação: diagrama da teoria do signo. 2. imp. São Paulo: Perspectiva, 1983.

COTTA, A. G. Música. In: CAMPELLO, B. S.; CALDEIRA, P. da T.; MACEDO, V. A. A. (Orgs.). Formas e expressões do conhecimento: introdução às fontes de informação. Belo Horizonte: Escola de Biblioteconomia da UFMG, 1998.

CUMMING, N. The sonic self: musical subjectivity and signification. Bloomington: Indiana University Press, 2000.

DOWNIE, J. S. The scientific evaluation of music information retrieval systems: foundations and future. Computer Music Journal, Cambridge (EUA), v. 28, n.2, p. 12-23, 2004. Disponível em: http://www.mitpressjournals.org/doi/abs/10.1162/014892604323112211. Acesso em: 19 out. 2018.

IBRI, I. A. Kósmos Noétos. São Paulo: Ed. Perspectiva,1992.

MCLANE, A. Music as information. In: CRONIN, B. Annual Review of Information Science and Technology. 37. ed. Medford: Information Today, 1996. p. 295-340.

MORAES, J. J. de. O que é música. 2. ed. Editora Brasiliense. São Paulo. 1983.

NÖTH, W. Panorama da Semiótica: de Platão a Pierce. São Paulo: Annablume, 2009.

PARENTE, B. L. M. A pedagogia musical de Schaffer e seus desdobramento no Brasil. 2008. Monografia (Licenciatura Plena em Educação Artística) - Centro de Letras e Artes, Universidade Federal do Estado do Rio de Janeiro, Rio de Janeiro, 2008. Disponível em:

http://www.domain.adm.br/dem/licenciatura/monografia/brunoparente.pdf. Acesso em: 8 maio 2017.

PEIRCE, C. S. Collected papers of charles sanders. Semiótica e Filosofia. São Paulo: Cultrix, 1975.

PEIRCE, C. S. Collected Papers, vols. 1-6, eds. Hartshorne, C.; WEISS, P., vols. 7-8, ed. BURKS, A. W. Cambridge, MA: Harvard University Press (citado como CP, seguido pelo número do volume e do parágrafo). - Port. (seleção): (1972. Semiótica e filosofia. São Paulo: Cultrix. (1974). Escritos coligidos. (= Os Pensadores XXXVI). São Paulo: Abril Cultural, pp. 1-200; e (1977). Semiótica. São Paulo: Perspectiva. 
PEIRCE, C. S. Semiotic and Significs: The Correspondence between Charles S. Peirce and Victoria Lady Welby. Bloomington: Indiana University Press, 1977. (Citado como SS).

PRATES, E. Semiótica: uma suave introdução. 2003. Disponível em:

http://www.robertexto.com/archivo/semiotica introducao.htm. Acesso em: 02 fe. 2018.

QUEIRÓZ, J. P. A música compõe o homem, o homem compõe a música. São Paulo: Editora Cultrix, 2000.

SANTAELLA, L. A teoria geral dos signos: como as linguagens significam as coisas. São Paulo: Pioneira, 2000.

SANTAELLA, L. A teoria geral dos signos: semiose e autogeração. São Paulo: Ática, 1995.

SANTAELLA, L. Matrizes da linguagem e pensamento: sonora, visual, verbal: aplicações na hipermídia. 3. ed. São Paulo: Iluminuras; FAPESP, 2009.

SANTAELLA, L. O que é semiótica. São Paulo: Brasiliense, 2007.

SANTAELLA, L. Semiótica aplicada. São Paulo: Pioneira Thompson Learning, 2002.

SAYÃO, L. F. Padrões para bibliotecas digitais abertas e interoperáveis. Encontros Bibli: revista eletrônica de Biblioteconomia e Ciência da Informação, Florianópolis, n. esp., 10 sem. 2007. Disponível em: http://www.periodicos.ufsc.br/index.php/eb/article/view/378/436. Acesso em: 19 out. 2018.

SCHAFFER, M. O ouvido pensante/R. Murray Schaffer. São Paulo: Fundação Editora da UNESP, 1991.

SILVEIRA, L. F. B. da. Curso de Semiótica Geral. Editora Quartier Latin do Brasil. São Paulo. 2007. 